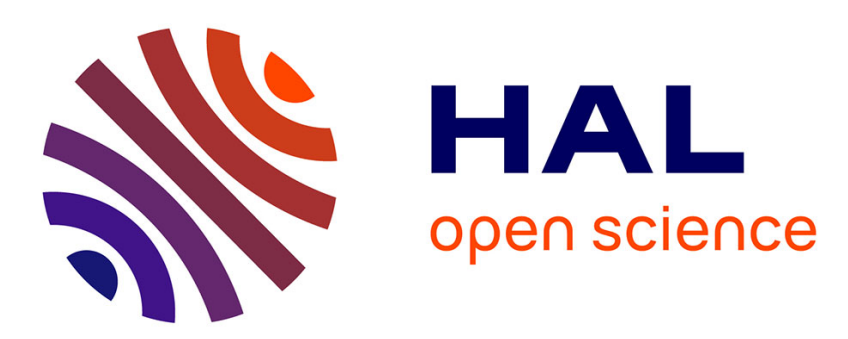

\title{
Liquid-Liquid Extraction of Cobalt(II), Nickel(II) and Manganese(II) from Acidic Chloride Media
}

Alexandre Chagnes, Kateryna Omelchuk

\section{To cite this version:}

Alexandre Chagnes, Kateryna Omelchuk. Liquid-Liquid Extraction of Cobalt(II), Nickel(II) and Manganese(II) from Acidic Chloride Media. Extraction 2018: Proceedings of the First Global Conference on Extractive Metallurgy, Aug 2018, Ottawa, Canada. hal-02270376

\section{HAL Id: hal-02270376 \\ https://hal.univ-lorraine.fr/hal-02270376}

Submitted on 26 Aug 2019

HAL is a multi-disciplinary open access archive for the deposit and dissemination of scientific research documents, whether they are published or not. The documents may come from teaching and research institutions in France or abroad, or from public or private research centers.
L'archive ouverte pluridisciplinaire HAL, est destinée au dépôt et à la diffusion de documents scientifiques de niveau recherche, publiés ou non, émanant des établissements d'enseignement et de recherche français ou étrangers, des laboratoires publics ou privés. 


\title{
Liquid-liquid extraction of cobalt(II), nickel(II) and manganese(II) from acidic chloride media
}

\author{
Alexandre Chagnes ${ }^{1 *}$ and Kateryna Omelchuk ${ }^{1}$ \\ ${ }^{1}$ GéoRessources - UMR CNRS 7359-CREGU-Université de Lorraine, 2 Rue du Doyen \\ Roubault 54518 Vandoeuvre les Nancy Cedex (France). \\ ${ }^{2}$ PSL Research University, Chimie ParisTech - CNRS, Institut de Recherche de Chimie \\ Paris, 11 rue Pierre et Marie Curie, 75005 Paris, France \\ * : Corresponding author : alexandre.chagnes@univ-lorraine.fr
}

\section{Abstract}

The extraction properties of two synthesized cationic exchangers, i.e. bis(1,3-dibutoxypropan-2yl) phosphoric acid (BiDiBoPP) and bis(1,3-diisobutoxypropan-2-yl) phosphoric acid (IPA), have been studied for the liquid-liquid extraction of $\mathrm{Co}(\mathrm{II}), \mathrm{Ni}(\mathrm{II})$ and $\mathrm{Mn}$ (II) contained in $1 \mathrm{M} \mathrm{HCl}$. A comparison of the extraction properties of these extractants diluted in kerosene with Cyanex ${ }^{\circledR} 272$ shows BiDiBoPP and IPA extract advantageously at lower $\mathrm{pH}$ than Cyanex ${ }^{\circledR} 272$ and a better $\mathrm{Co}(\mathrm{II})-\mathrm{Mn}(\mathrm{II})$ separation is achieved using BiDiBoPP or IPA than with Cyanex ${ }^{\circledR} 272$.

Keywords: Cobalt, Nickel, Manganese, Solvent extraction.

\section{Introduction}

Nickel is mainly extracted from laterite and sulphide ores while cobalt is mainly extracted from linneaite and cobaltine and manganese is found in the rocks of pyrolusite, haussmannite and braunite [1]. Pyrometallurgy is still the preferred technology to recover these metals in addition to their recovery as a by-product in copper ores. Nevertheless, laterite ores containing both nickel, cobalt and other metals of economic interest are increasingly being treated by hydrometallurgical methods or methods combining both pyrometallurgy and hydrometallurgy [2]. However, the trend is changing in favor of hydrometallurgy because of the negative environmental impact of pyrometallurgy and its high energy consumption, and because pyrometallurgy is not adapted to extract metals from the new and leaner polymetallic resources.

In order to cope with the increase in world demand for cobalt, nickel and manganese, other resources are also likely to be exploited in the future. In the short term, spent lithium-ion batteries appear as a complementary resource in cobalt, nickel and manganese, especially with the emergence of electric vehicles that currently rely on positive electrodes containing these metals such as $\mathrm{Li}_{1 / 3} \mathrm{Co}_{1 / 3} \mathrm{Mn}_{1 / 3} \mathrm{O}_{2}, \mathrm{LiMn}_{2} \mathrm{O}_{4}$, or older technologies such as $\mathrm{LiCoO}_{2}$ or $\mathrm{LiNiO}_{2}[3,4]$. In the longer term, marine nodules are also likely to supply the market with cobalt, nickel and manganese [5]. 
The development of new hydrometallurgical processes for the recovery of cobalt, nickel and manganese from new polymetallic ores while keeping as low as possible the environmental footprint and the cost of the process is therefore a central concern. While cobalt and nickel separation in acidic chloride and sulfate media is easily performed by liquid-liquid extraction by using the well-established Cyanex ${ }^{\circledR} 272$ extractant (bis-(2,4,4-trimethylpentyl) phosphinic acid), the separation of manganese from cobalt-nickel by solvent extraction is more difficult. Such a separation is presently performed using precipitation unit operations, which may increase the complexity of the process and its cost. The development of new extracting agents and the corresponding flowsheets incorporating them is particularly important to achieve the desired selectivity. This paper deals with the investigation of the extraction of $\mathrm{Ni}(\mathrm{II}), \mathrm{Co}$ (II) and $\mathrm{Mn}$ (II) from acidic chloride media by two new extractants, i.e. bis(1,3-dibutoxypropan-2-yl) phosphoric acid (BiDiBoPP) and bis(1,3-diisobutoxypropan-2-yl) phosphoric acid (IPA) shown in Figure 1.

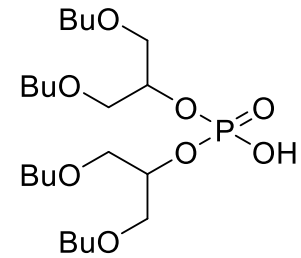

(a)

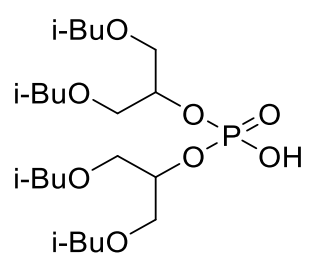

(b)

Figure 1. Chemical structure of (a) bis(1,3-dibutoxypropan-2-yl) phosphoric acid (BiDiBoPP) and (b) bis(1,3-diisobutoxypropan-2-yl) phosphoric acid (IPA).

\section{Experimental section}

\section{Synthesis of organophosphorus acids}

Phosphorus trichloride (Fisher Scientific, purity 99\%), pyridine (Fisher Scientific, purity 99\%), 2-methyl-1-propanol (Fisher Scientific, purity 99\%), 1-butanol (Fisher Scientific, purity 99,5\%), iodine (Fisher Scientific, purity 99\%), sodium (Sigma Aldrich purity $\geq 99$.8and 1,3dichloro-2-propanol (TCI, purity $>98 \%$ ) were used as delivered.

The synthesis of BiDiBOPP was performed according to the procedure previously published by Beltrami et al. [6] (Scheme 1).

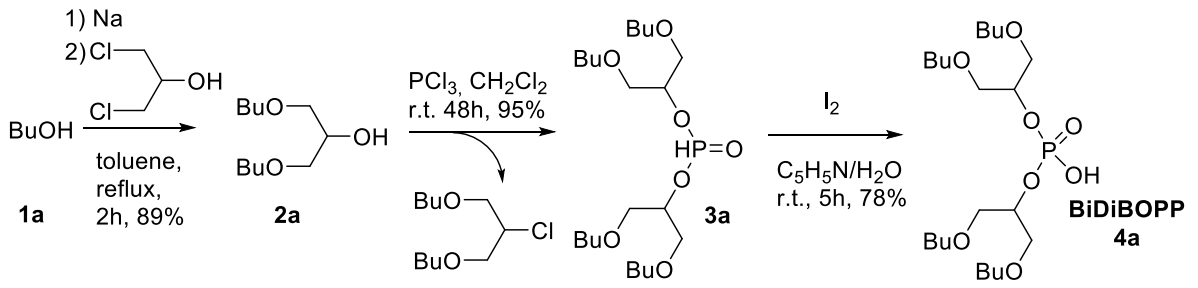

Scheme 1. Synthesis route to produce BiDiBOPP.

The 1,3-dibutoxy-2-propanol (2a) was synthesized by reaction of $n$-butanol and 1,3-dichloro2-propanol in the presence of sodium metal. The reaction of $2 \mathrm{a}$ with phosphorus trichloride $\left(\mathrm{PCl}_{3}\right)$ at room temperature led to bis(1,3-dibutoxypropan-2-yl) phosphite (3a) at a $78 \%$ yield. After purification, $3 \mathrm{a}$ was oxidized by $\mathrm{I}_{2}$ in pyridine-water mixture to form bis(1,3dibutoxypropan-2-yl) phosphoric acid (BiDiBOPP, 4a). The same reactions as in Scheme 1, but 
replacing n-butanol by 2-methyl-1-propanol was used for synthesizing bis(1,3diisobutoxypropan-2-yl) phosphoric acid (IPA). Yields of $78 \%$ and $95 \%$ with purities of $95 \%$ and $94 \%$ were found by GC-MS, ESI-MS and NMR $\left({ }^{1} \mathrm{H},{ }^{31} \mathrm{P},{ }^{13} \mathrm{C}\right)$ for BiDiBOPP and IPA, respectively.

Liquid-liquid extraction procedure

Cobalt(II) nitrate hexahydrate $\left(\mathrm{CoCl}_{2}\right.$, Sigma Aldrich, purity $\geq 98 \%$ ), nickel(II) chloride hexahydrate $\left(\mathrm{NiCl}_{2} \cdot 6 \mathrm{H}_{2} \mathrm{O}\right.$, Sigma Aldrich, purity $\left.\geq 98 \%\right)$, manganese(II) chloride tetrahydrate $\left(\mathrm{MnCl}_{2} \cdot 4 \mathrm{H}_{2} \mathrm{O}\right.$, Sigma Aldrich, purity $\left.\geq 98 \%\right)$ were used to prepare feed solutions for liquid-liquid extraction experiments. Feed solutions of $\mathrm{Ni}(\mathrm{II}), \mathrm{Co}(\mathrm{II})$ and $\mathrm{Mn}(\mathrm{II})$ at $1.17 \mathrm{~g} / \mathrm{L}(0.02 \mathrm{~mol} / \mathrm{L}), 1.18$ $\mathrm{g} / \mathrm{L}(0.02 \mathrm{~mol} / \mathrm{L})$ and $1.1 \mathrm{~g} / \mathrm{L}(0.02 \mathrm{~mol} / \mathrm{L})$ respectively, were prepared by dissolving the required amount of salts in $1 \mathrm{M}$ hydrochloric acid solution.

Cyanex $^{\circledR} 272$ (Solvay-Cytec, purity $>85 \%$ ) and Ionquest ${ }^{\circledR} 801$ (2-ethylhexylphosphonic acid, mono-2-ethylhexyl ester, Solvay, purity not specified) were used without further purification. Extraction solvents were prepared by diluting the commercial and synthesized extractants in kerosene (Sigma Aldrich, reagent grade, low odor).

The extraction properties of the organophosphorus acids towards $\mathrm{Co}(\mathrm{II}), \mathrm{Ni}(\mathrm{II})$ and $\mathrm{Mn}$ (II) in acidic chloride media were evaluated by plotting the metal distribution curves (extraction efficiency $\% \mathrm{E}$ vs. $\mathrm{pH}$ ). In order to plot the metal-distribution curves, the $\mathrm{pH}$ values of the aqueous phases were adjusted by using $\mathrm{NaOH}$ and $\mathrm{HCl}$ (standard solution, Alfa Aesar). Batch experiments were conducted at $25^{\circ} \mathrm{C}$ in a flask containing equal volumes of aqueous and organic phases $\left(10 \mathrm{~mL} ; \mathrm{V}_{\text {org }} / \mathrm{V}_{\mathrm{aq}}=1\right)$. The two-phase system was shaken with a Thermoshaker (Gerhardt) at $100 \mathrm{rpm}$ for 15 minutes. Preliminary experiments on the kinetics of extraction of $\mathrm{Ni}(\mathrm{II}), \mathrm{Co}(\mathrm{II})$ and $\mathrm{Mn}$ (II) showed that equilibrium was reached in all cases within 5 minutes of contact. After phase separation, the aqueous phase was filtered on a hydrophilic filter (Minisart NML $16555 \mathrm{~K}$, cellulose acetate, $0.45 \mu \mathrm{m}, \mathrm{d}=28 \mathrm{~mm}$ ) and the equilibrium $\mathrm{pH}$ of the aqueous phase was measured. Metal concentrations in aqueous solutions were determined by ICP-OES (ICAP 6000 Series, Thermo Scientific) at $243.7 \mathrm{~nm}$ for nickel, $237 \mathrm{~nm}$ for cobalt and $257 \mathrm{~nm}$ for manganese after diluting the sample in hydrochloric acid (ICP standard solution, 37\%, VWR). Metal ion concentration transferred from the aqueous phase into the organic phase was then calculated by mass balance in order to obtain the extraction efficiency. Experiments were duplicated and the experimental error on the distribution coefficients of metals was estimated to be within $5 \%$.

\section{Result and Discussion}

Figure 2 shows the extraction isotherms of $\mathrm{Co}(\mathrm{II}), \mathrm{Ni}(\mathrm{II})$ and $\mathrm{Mn}(\mathrm{II})$ from acidic chloride solution by Cyanex ${ }^{\circledR} 272$ and the two extractants synthesized in the present work, i.e. BiDiBOPP and IPA. The presence of oxygen atoms in the chemical structure of BiDiBOPP and IPA shifts the extraction curves of $\mathrm{Co}(\mathrm{II}), \mathrm{Ni}(\mathrm{II})$ and $\mathrm{Mn}(\mathrm{II})$ towards the low $\mathrm{pH}$ values since $\mathrm{pH}$ of half extraction $\mathrm{pH}_{1 / 2}=3.8,4.2$ and 6.5 for $\mathrm{Co}(\mathrm{II}), \mathrm{Mn}(\mathrm{II})$ and $\mathrm{Ni}(\mathrm{II})$, respectively, when Cyanex ${ }^{\circledR} 272$ is used whereas $\mathrm{pH}_{1 / 2}=2.3,1.5$ and 2.5 and $\mathrm{pH}_{1 / 2}=2.3,1.5$ and 3 for the same metals with BiDiBOPP and IPA respectively. Such an observation can be explained by a decrease of the $\mathrm{pKa}$ values due to the presence of oxygen atoms in the alkyl chains of the extractant [7]. Extraction properties of BiDiBOPP and IPA are very close as they have similar chemical structure. Therefore, no significant influence of the branching of the alkyl chains of the organophosphorus 
compounds on the extraction properties of $\mathrm{Co}(\mathrm{II}), \mathrm{Ni}(\mathrm{II})$ and $\mathrm{Mn}(\mathrm{II})$ is observed. The decrease of the $\mathrm{pH}$ of extraction when Cyanex ${ }^{\circledR} 272$ is replaced by BiDiBOPP and IPA is interesting potentially reducing for the extraction process operating cost.

(a)

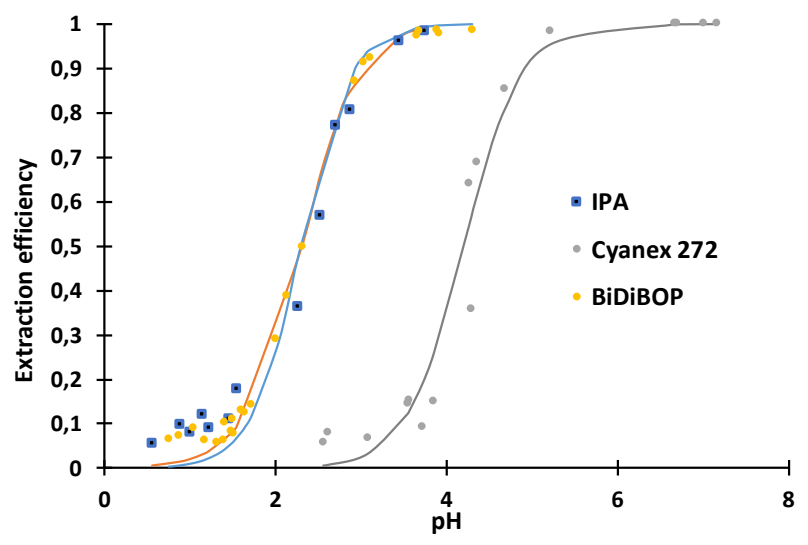

(b)

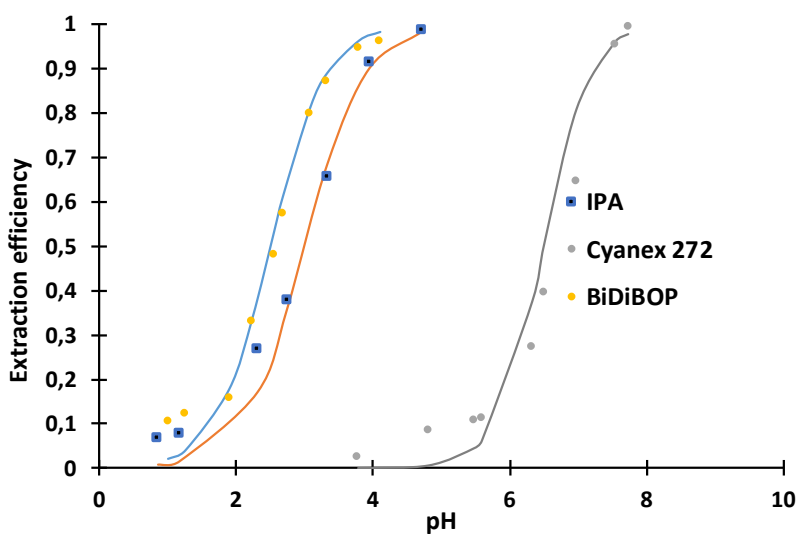

(c)

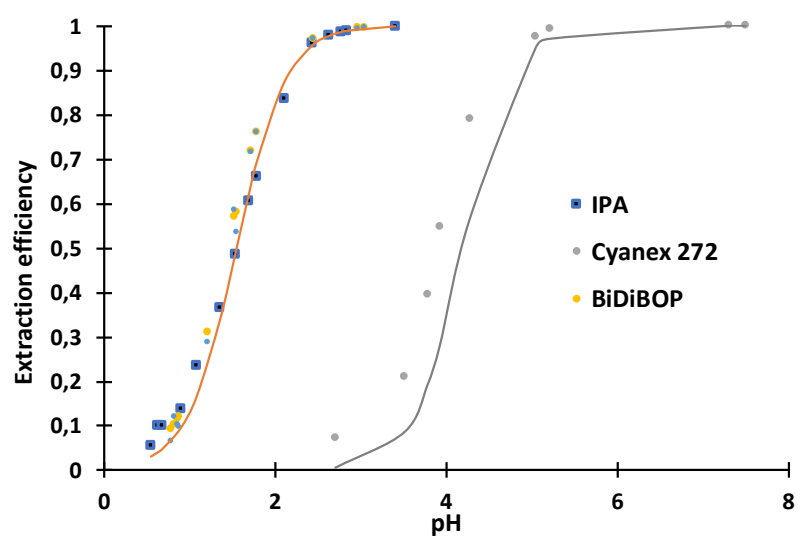

Figure 2. Extraction efficiency of (a) $\mathrm{Co}(\mathrm{II})$, (b) $\mathrm{Ni}(\mathrm{II})$ and (c) $\mathrm{Mn}$ (II) by Cyanex ${ }^{\circledR} 272$, BiDiBOPP and IPA diluted in kerosene as a function of equilibrium $\mathrm{pH}$. Temperature $=25^{\circ} \mathrm{C}$; phase volume ratio $\mathrm{V}_{\text {org }} / \mathrm{V}_{\mathrm{aq}}=1$; chloride concentration=1 $\mathrm{M}$.

Indeed, solvent extraction is used to recover metals from leaching solutions which are usually acidic. Therefore, it is necessary to add an alkaline reagent to increase the $\mathrm{pH}$ of the leaching solution in order to perform the extraction. For instance, the use of Cyanex ${ }^{\circledR} 272$ to extract $\mathrm{Co}$ (II) and $\mathrm{Ni}$ (II) requires an increase of the $\mathrm{pH}$ of the leach solution from around 1-2 to 4.2 and 6.5 respectively. By replacing Cyanex ${ }^{\circledR} 272$ with BiDiBOPP or IPA, less neutralizing alkaline reagent should be needed as it will only be necessary to raise the $\mathrm{pH}$ from 1-2 to 2.3 and 3 , respectively.

Furthermore, it is interesting to point out that the use of BiDiBOPP or IPA allows the separation of $\mathrm{Mn}$ (II) from $\mathrm{Co}(\mathrm{II})$ and $\mathrm{Ni}$ (II) to be envisaged, since $\mathrm{pH}_{1 / 2}$ for $\mathrm{Mn}$ (II) extraction is 1.5 and $\mathrm{pH}_{1 / 2}$ values for $\mathrm{Co}(\mathrm{II})$ and $\mathrm{Ni}(\mathrm{II})$ are 2.3 and 2.5-3. Conversely, $\mathrm{Mn}$ (II)-Co(II) separation 
using Cyanex ${ }^{\circledR} 272$ is not possible since the extraction curves of $\mathrm{Co}(\mathrm{II})$ and $\mathrm{Mn}(\mathrm{II})$ are too similar in terms of percent extraction versus $\mathrm{pH}$.

Based on the above results, it is therefore possible to envisage the flowsheet proposed in Figure 3 to separate $\mathrm{Co}(\mathrm{II})-\mathrm{Ni}(\mathrm{II})-\mathrm{Mn}$ (II) mixtures in acidic chloride media without performing any precipitation operation. For example in recycling cathode material from lithium-ion batteries, there are no elements present other than $\mathrm{Co}, \mathrm{Ni}$ and $\mathrm{Mn}$. For ores, additional treatment might be needed because of the presence of other impurities such as iron that must be removed.

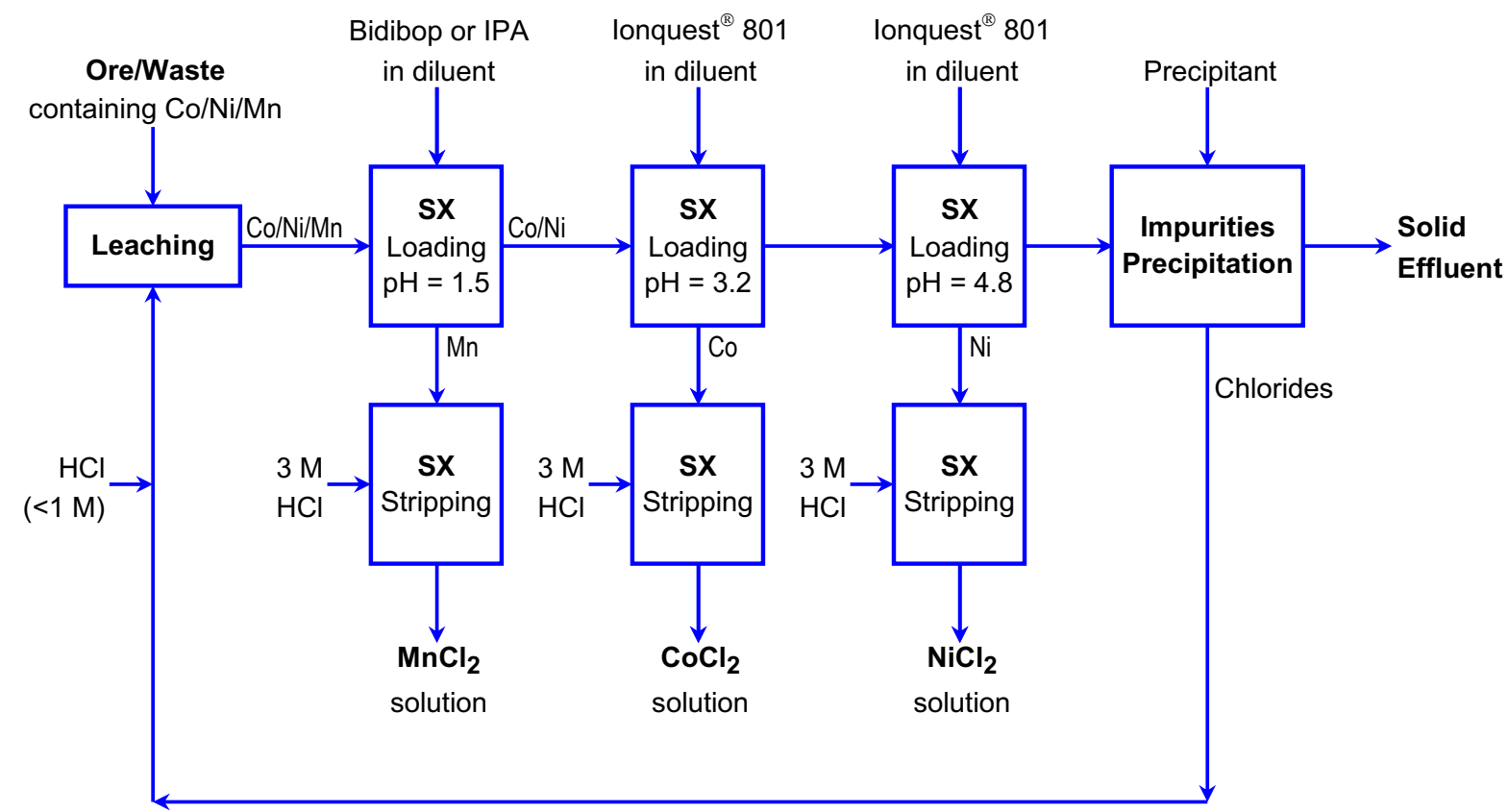

Figure 3 Proposed flowsheet for separation of $\mathrm{Co}, \mathrm{Mn}$ and $\mathrm{Ni}$

\section{References}

1. Lateef Ibrahim, B. A., Adekola, F. A., Bale, R. B., Ghosh, M. K., Sheik, Olushola, A. R. S. R. Pradhan, Ayanda, S. and Folorunsho, I. O. (2014), "Hydrometallurgical Processing of Manganese Ores: A Review". Journal of Minerals and Materials Characterization and Engineering 2 (3):230-47.

2. Sole, K. C., and P.M Cole. (2002), "Purification of Nickel by Solvent Extraction" In Ion Exchange and Solvent Extraction Vol. 15. New York: Marcel Dekker.

3. Chagnes, A., Swiatowska, J. eds. (2015), "Lithium Process Chemistry: Resources, Extraction, Batteries, and Recycling" Amsterdam Boston Heidelberg: Elsevier.

4. Chagnes, A., Pospiech, B (2013), "A Brief Review on Hydrometallurgical Technologies for Recycling Spent Lithium-Ion Batteries". Journal of Chemical Technology \& Biotechnology 88 (7):1191-1199.

5. Senanayake, G., (2011), "Acid Leaching of Metals from Deep-Sea Manganese Nodules - A Critical Review of Fundamentals and Applications". Minerals Engineering 24 (13):1379-96.

6. Sterk, R., and J.K. Stein, (2015) "Seabed Mineral Resources: A Review of Current Mineral Resources and Future Developments". Deep Sea Mining Summit, Aberdeen: Scotland 27.

7. Beltrami, D., Chagnes, A., Haddad, M., Laureano, H., Mokhtari, H., Courtaud, Jugé, S. and Cote, G. (2013), "Development of New Cationic Exchangers for the Recovery of Uranium (VI) from Concentrated Phosphoric Acid", Sep. Sci. Technol. 48(3):480-486.

8. Omelchuk, K, Szczepanski, P., Shrotre, A., Haddad, M., Chagnes, A. (2017) "Effects of structural changes of new organophosphorus cationic exchangers on a solvent extraction of cobalt, nickel and manganese from acidic chloride media" RSC Advances 7:5660-5668. 